\title{
O MOVIMENTO PARANISTA E A REVISTA ILLUSTRAÇÃO PARANAENSE
}

\author{
Luis Afonso Salturi*
}

RESUMO: A Illustração Paranaense: mensario paranista de arte e actualidades foi uma revista que circulou no Estado do Paraná entre 1927 e 1930, período em que o Movimento Paranista vivia seu auge. Contando com práticas de diferentes campos, esse movimento cultural se desenvolveu ao mobilizar a consciência e ações de artistas e intelectuais em prol de uma identidade local. Pretende-se tomar como objeto de estudo o papel da referida revista na construção, tanto de um discurso, como de imagens, que pretendiam definir uma identidade paranaense ou paranista. O objetivo principal do artigo consiste em entender como o periódico exerceu seu papel como veículo de divulgação das ideias e obras dos representantes do Movimento Paranista, na especificidade das artes gráficas e plásticas. Toma-se como hipótese que o interesse político não sobressaía ao interesse artístico e cultural, pois ambos seguiam para a mesma direção. Lançando mão de dados estatísticos, pretende-se investigar a rede de relações constituída pela equipe editorial da revista e seus colaboradores.

PALAVRAS-CHAVE: Illustração Paranaense; Movimento Paranista; arte paranaense: aspectos sociais.

ABSTRACT: The Illustracão Paranaense: mensario paranista de arte e actualidades was a magazine that circulated in Paraná, Brazil between 1927 and 1930, during which the Paranista Movement lived its heyday. Counting practices of different fields, this cultural movement developed to mobilize awareness and actions of artists and intellectuals in favor of a local identity. The intention is to take as object of study the role of that magazine in the construction of both a speech, as images, they intended to set a paranaense identity.

* Doutor em Sociologia pela Universidade Federal do Paraná. Contato: lasalturi@yahoo.com.br. 
The aim of this article is to understand how the periodic exercised its role as a vehicle for the dissemination of ideas and works of representatives of Paranista Movement, the specificity of the visual arts. Is taken as hypothesis that political interest is not excelled on the artistic and cultural interest, because both followed the same direction. Drawing on statistical data, the intention is investigate the relationship network formed by the editorial staff of the magazine and its contributors.

KEYWORDS: Illustraşão Paranaense; Paranista Movement; Brazilian art: social aspects.

\section{INTRODUÇÃO}

Conforme aponto em Gerações de artistas plásticos e suas práticas: Sociologia da arte paranaense das primeiras décadas do século XX (SALTURI, 2011), o Movimento Paranista foi um movimento cultural com fortes vínculos políticos, que ocorreu no Estado do Paraná e que teve seu auge entre 1927 e 1930, quando seus ideais estavam organizados e institucionalizados em forma de práticas culturais. A literatura, a poesia, o teatro, a história, a pintura, a escultura, o desenho, a arquitetura, a música, a moda, todos que produziram nessas áreas destacavam em suas obras temas relacionados a elementos da flora e da fauna considerados representativos da identidade paranaense (ou paranista ${ }^{1}$ ). O pinheiro-do-paraná, a gralha-azul e os índios da região são os elementos mais marcantes e que persistiram ao longo dos anos. Também tiveram pouca repercussão ou não foram aceitos como

1 O Programma Geral do Centro Paranista apresenta a definição do termo "paranista" como “amigo do Paraná, contribuinte do seu progresso" (MARTINS, 1927). Em outra publicação de Romário Martins aparece a seguinte definição: "Paranista é simbolicamente aquele que em terra do Paraná lavrou um campo, vadeou uma floresta, lançou uma ponte, construiu uma máquina, dirigiu uma fábrica, compôs uma estrofe, pintou um quadro, esculpiu uma estátua, redigiu uma lei liberal, praticou a bondade, iluminou um cérebro, evitou uma injustiça, educou um sentimento, reformou um perverso, escreveu um livro, plantou uma árvore" (MARTINS, 1948, p. 38). É preciso destacar também a diferença entre os termos Movimento Paranista e paranismo. Este último, que não será tratado aqui, foi tema de outro artigo no qual analiso e critico a bibliografia existente sobre o tema (SALTURI, 2009). 
representativos da região, como a palmeira, a guabiroba, a pitanga, a manga, o maracujá, o café e a erva-mate ${ }^{2}$.

O Movimento Paranista não teve uma relação direta com a Semana de Arte Moderna, pois as propostas desta tiveram pouco efeito em Curitiba. É preciso considerar as especificidades do campo cultural paranaense do início do século XX, principalmente porque os interesses dos artistas e intelectuais paranaenses eram distintos dos paulistas. Os primórdios do Movimento Paranista se devem ao Movimento Simbolista que ocorreu no Paraná, e seu fim, ao Estado Novo, que suprimiu as manifestações regionalistas.

A principal publicação que remete ao Movimento Paranista é a revista Illustração Paranaense, criada em 1927, pelo cineasta, fotógrafo e jornalista João Baptista Groff. Esse periódico refletia os temas e o ideário em voga naquele momento, apresentava uma ótima qualidade gráfica e editorial e contava com a colaboração de artistas e intelectuais. Essa publicação, que hoje se tornou rara, pode ser encontrada na Casa da Memória de Curitiba (coleção completa), na Biblioteca Pública do Paraná (coleção parcial) e no Museu Paranaense (coleção parcial).

Esse artigo tem como objetivo analisar como a Illustração Paranaense exerceu o papel de veículo de divulgação do Movimento Paranista, a partir de um discurso textual e de uma linguagem visual que faziam referência a um Paraná idealizado. Por essa via, pretende-se identificar a posição de poder dos diversos campos em que houve algum tipo de manifestação do referido movimento, a partir da produção de seus principais representantes. Para entender como esses profissionais estavam ligados entre si, optou-se por utilizar como suporte teórico os autores Norbert Elias e Pierre Bourdieu. A partir dos conceitos sociológicos habitus e campo (BOURDIEU, 1996) e configuração (ELIAS, 1999), é possível compreender muitos aspectos das ações dos indivíduos em questão, tomando como via de acesso as teias de interdependência que formavam entre si.

\footnotetext{
${ }^{2} \mathrm{O}$ escultor e desenhista João Turin realizou vários estudos com esses elementos da flora local. Porém, essas obras são menos conhecidas, pois permaneceram apenas como projetos.
} 
Em relação à perspectiva analítica, procurou-se direcionar as análises para o que a socióloga francesa Nathalie Heinich chama de "direções mais inovadoras da Sociologia da Arte recente" (HEINICH, 2008). Nesta, a arte não é mais o ponto de partida do questionamento, mas o ponto de chegada, pois o que interessa à pesquisa não é interior à arte - abordagem "interna", centrada nas obras -, nem exterior a ela - abordagem socializante "externa", centrada nos contextos. Interessa o que a produz e o que ela mesma produz, como qualquer elemento de uma sociedade, já que a arte é uma dentre outras possibilidades de atividade social, possuindo características próprias.

\section{ARTE E SOCIEDADE NA ILLUSTRAÇÃO PARANAENSE}

As artes gráficas tiveram um grande impulso em Curitiba a partir de 1880, quando o serviço de tipografia passou a utilizar o prelo mecânico. Esse equipamento viabilizou o lançamento de revistas, a edição de livros e a maior periodicidade de jornais. O levantamento a seguir (quadro 1), realizado a partir do arquivo catalográfico da Biblioteca Pública do Paraná, fornece uma ideia do número de periódicos que circularam no final da década de 1920:

QUADRO 1 - Periódicos Paranaenses - 1927 até 1930.

\begin{tabular}{|l|c|c|c|c|}
\hline Revista & 1927 & 1928 & 1929 & 1930 \\
\hline A Cidade & & & $\mathrm{X}$ & \\
\hline A Cruzada & $\mathrm{X}$ & $\mathrm{X}$ & $\mathrm{X}$ & $\mathrm{X}$ \\
\hline A Semana Ilustrada & $\mathrm{X}$ & & & \\
\hline Almanach do Paraná & & & $\mathrm{X}$ & \\
\hline Almanach dos Municípios & $\mathrm{X}$ & $\mathrm{X}$ & $\mathrm{X}$ & $\mathrm{X}$ \\
\hline Almanaque da Polícia Militar & $\mathrm{X}$ & & & \\
\hline Alvorada & & & $\mathrm{X}$ & \\
\hline Boas Estradas & & $\mathrm{X}$ & & \\
\hline Boletim do Archivo Municipal de Curitiba & $\mathrm{X}$ & $\mathrm{X}$ & $\mathrm{X}$ & $\mathrm{X}$ \\
\hline
\end{tabular}

Temáticas, Campinas, 22, (43): 127-158, fev./jun. 2014 


\begin{tabular}{|l|c|c|c|c|}
\hline Boletim Mensal do Departamento de Comércio & & & & $\mathrm{X}$ \\
\hline Illustração Paranaense & $\mathrm{X}$ & $\mathrm{X}$ & $\mathrm{X}$ & $\mathrm{X}$ \\
\hline Indicador Commercial Paranaense & & & & $\mathrm{X}$ \\
\hline Kalendarz "Ludu" & $\mathrm{X}$ & & & \\
\hline Luz de Krotona & $\mathrm{X}$ & & & \\
\hline Neue Heimat & & & $\mathrm{X}$ & \\
\hline O Cruz̨eiro & $\mathrm{X}$ & & & \\
\hline O Itiberê & $\mathrm{X}$ & $\mathrm{X}$ & $\mathrm{X}$ & $\mathrm{X}$ \\
\hline O Mate & & & $\mathrm{X}$ & $\mathrm{X}$ \\
\hline Paraná Judiciário & $\mathrm{X}$ & $\mathrm{X}$ & $\mathrm{X}$ & $\mathrm{X}$ \\
\hline Paraná Progresso & & & & $\mathrm{X}$ \\
\hline Prata da Casa & $\mathrm{X}$ & $\mathrm{X}$ & $\mathrm{X}$ & $\mathrm{X}$ \\
\hline Pryjaciel Rodziny & & & & $\mathrm{X}$ \\
\hline Revista A Rua & & & & $\mathrm{X}$ \\
\hline Revista Agrícola & $\mathrm{X}$ & & & \\
\hline Revista da Academia de Letras do Paraná & $\mathrm{X}$ & & & \\
\hline Revista de Agronomia do Centro Acadêmico de Agronomia & & & & $\mathrm{X}$ \\
\hline Semeia Semeador & & $\mathrm{X}$ & & \\
\hline Sanctuarium do Rocio & & & $\mathrm{X}$ & \\
\hline Scientia et Labor & & & \\
\hline Volante & & & $\mathrm{X}$ \\
\hline
\end{tabular}

Fonte: Levantamento elaborado pelo autor com base no arquivo catalográfico da Seção Paranaense da Biblioteca Pública do Paraná.

Nota: As grafias dos nomes dos jornais e revistas seguem como no documento pesquisado. As revistas estão disponíveis em formato impresso e alguns exemplares em microfilme. Nesse levantamento foram excluídos guias e anuários.

Surgida no auge dessa fase de avanço técnico, a Illustração Paranaense: mensario paranista de arte e actualidades foi uma das revistas mais interessantes que o Estado do Paraná já teve, tendo servido também para expressar e promover os ideais dos representantes do Movimento Paranista. Fundada em 23 de novembro de 1927, esse periódico teve circulação até novembro 
de 1930. O quadro 2, a seguir, mostra em detalhes os números lançados durante os anos em que a mesma circulou:

QUADRO 2 - Edições da Revista Illustração Paranaense.

\begin{tabular}{|c|c|c|}
\hline Ano & Mês & Números \\
\hline 1927 (I) & Novembro & 1 \\
\hline 1927 (I) & Dezembro & 2 \\
\hline 1928 (II) & Janeiro & 1 \\
\hline 1928 (II) & Fevereiro & 2 \\
\hline 1928 (II) & Março & 3 \\
\hline 1928 (II) & Abril & 4 \\
\hline 1928 (II) & Maio & 5 \\
\hline 1928 (II) & Junho & 6 \\
\hline 1928 (II) & Julho & 7 \\
\hline 1928 (II) & Agosto & 8 \\
\hline 1928 (II) & Setembro & 9 \\
\hline 1928 (II) & Outubro / Novembro & 10 e 11 \\
\hline 1928 (II) & Dezembro & 12 \\
\hline 1929 (III) & Janeiro / Fevereiro & $1 \mathrm{e} 2$ \\
\hline 1929 (III) & Março & 3 \\
\hline 1929 (III) & Abril & 4 \\
\hline 1929 (III) & Maio / Junho & 5 e 6 \\
\hline 1929 (III) & Junho / Julho & 7 e 8 \\
\hline 1929 (III) & Novembro & 8 a 11 \\
\hline 1929 (III) & Dezembro & 12 \\
\hline 1930 (IV) & Janeiro & 1 \\
\hline 1930 (IV) & Fevereiro & 2 \\
\hline 1930 (IV) & Março & 3 \\
\hline 1930 (IV) & Abril & 4 \\
\hline 1930 (IV) & Maio & 5 \\
\hline 1930 (IV) & Junho & 6 \\
\hline
\end{tabular}




\begin{tabular}{|c|c|c|}
\hline $1930(\mathrm{IV})$ & Julho & 7 \\
\hline $1930(\mathrm{IV})$ & Agosto & 8 \\
\hline $1930(\mathrm{IV})$ & Outubro & 9 \\
\hline $1930(\mathrm{IV})$ & Novembro & 10 \\
\hline $1933(\mathrm{~V})$ & Fevereiro & - \\
\hline
\end{tabular}

Fonte: Levantamento realizado pelo autor com base nos acervos da Biblioteca Pública do Paraná, do Museu Paranaense e da Casa da Memória de Curitiba.

O próprio subtítulo da revista já indica qual era sua proposta. Concentrando-se em temas e no ideário em voga naquele momento, procurava retratar o ambiente artístico e sociocultural da capital paranaense e do Estado, fazendo a cobertura de festas, comemorações e eventos sociais, como, por exemplo, os concursos de beleza Senhorita Curitiba e Musa da Primavera, organizados pela sua equipe editorial. Além da vida social, o periódico oferecia uma grande variedade cultural para seus leitores, intercalando poesias, contos, críticas de arte e crônicas com reportagens sobre os mais diversos assuntos. Dentre os temas dessas reportagens, merecem destaque as belezas naturais do litoral paranaense e da região de Foz do Iguaçu, o processo de urbanização pelo qual passava a capital e o Estado do Paraná.

Quanto à apresentação gráfica, cada número da revista apresentava capa com cores que variavam a cada mês. De autoria do escultor e desenhista João Turin, a capa trazia um desenho com um homem de braços abertos fazendo analogia a um pinheiro (Figura 1), uma alusão às lendas indígenas dos escritos do historiador Romário Martins, muitos deles reproduzidos na página de abertura do periódico. 


\section{IIIUSIDACAO DADANATNSE?}

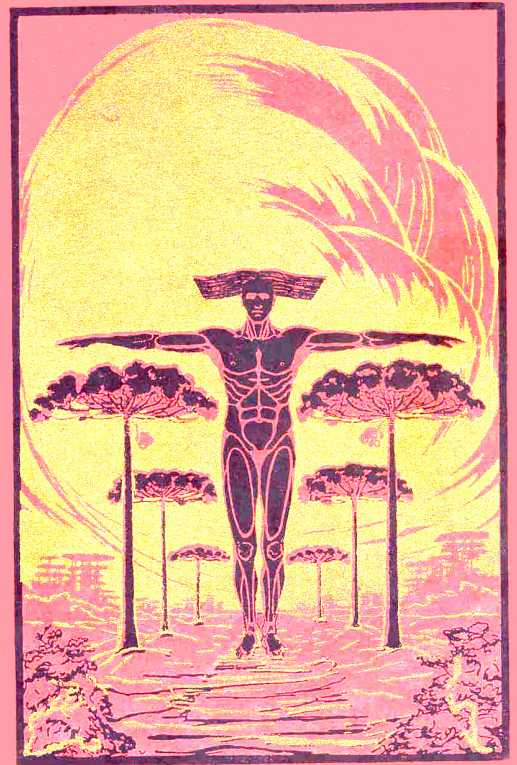

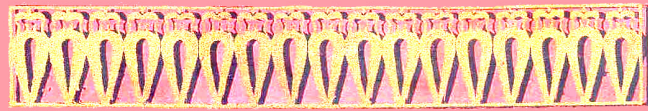

Figura 1 - Turin, J. Capa da Revista Illustração Paranaense. 1930. In: Illustração Paranaense (1930, n. 1, jan.). 
Ao longo do período de existência da revista, esse desenho de capa se apresentou em duas diferentes versões, mas sem nenhuma mudança quanto ao tema representado. No que se refere à linguagem artística, o desenho carrega fortes referências à Arte Renascentista. O homempinheiro de João Turin se assemelha ao Homem Vitruviano, desenho que Leonardo da Vinci fez num dos seus cadernos de anotações, em que este descreve as proporções do corpo humano (prancha 1).

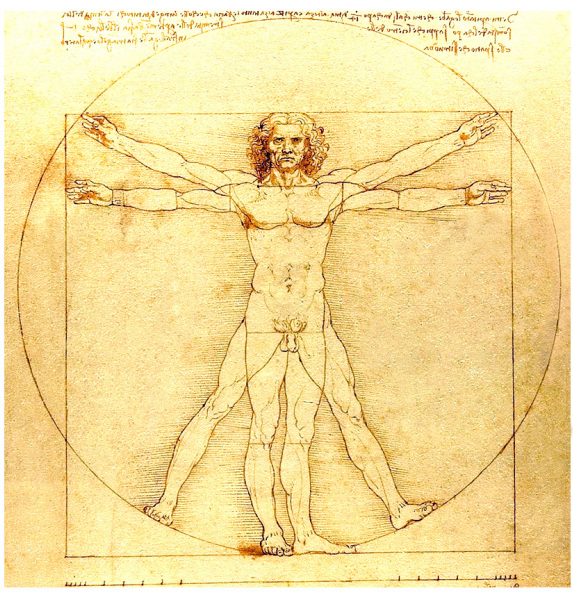

(1)

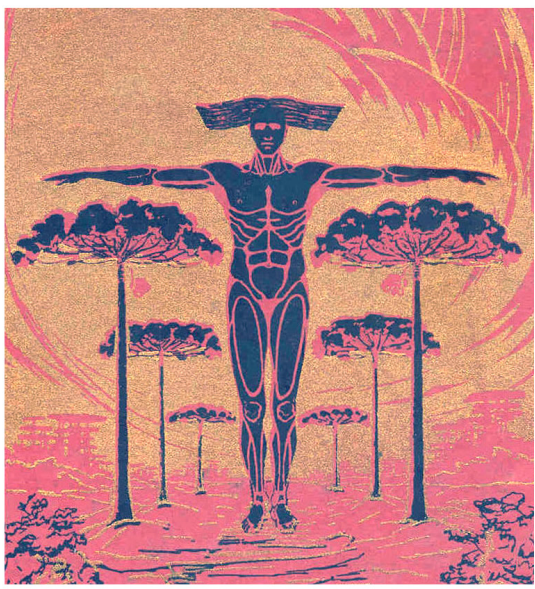

(2)

PRANCHA 1 - Homem Vitruviano e Homem-Pinheiro.

NOTA: (1) DA VINCI, L. Homem Vitruviano - Detalhe. 1490. Desenho á lápis e tinta; 34 x 24 cm. Gallerie dell’ Accademia. Veneza. Itália.

(2) TURIN, J. Capa da revista Illustração Paranaense - Detalhe. 1930. In: Illustração Paranaense (1930, n. 1 , jan.).

O Homem Vitruviano tem como tema uma figura masculina desnuda elaborada em duas posições sobrepostas com os braços inscritos num círculo e num quadrado. Assim como no desenho renascentista, os braços do homem-pinheiro estão estendidos, suas pernas quase se juntam e seu 
pé direito está virado para o lado. O fundo é formado por um círculo de tinta, que lembra muito o desenho de Da Vinci, no qual o homem está dentro de um círculo. No desenho de João Turin, o homem se equipara à anatomia do pinheiro, pois seus cabelos são ondulados, compridos e se expandem para as laterais, assemelhando-se ao formato da copa da árvore. Atrás do homem, três pinheiros em cada lado formam uma sequência e facilitam a percepção dessa semelhança.

Em conjunto, a capa e outros elementos visuais contribuem na definição do estilo peculiar da revista, não só em relação à sua apresentação gráfica, mas também no que se refere à articulação entre imagem e texto. Nesse ponto, considerando as possibilidades de comunicação imagética e textual, pois, conforme define o filósofo Vilém Flusser, "as imagens são superfícies que pretendem representar algo", elas não são símbolos com significados precisos, não são denotativas, pois oferecem aos seus receptores um espaço interpretativo, elas são símbolos "conotativos" que se diferenciam dos textos porque estes são signos da escrita em linhas. O "vaguear do olhar" do espectador para as imagens é circular e não linear, já que tende a voltar a contemplar aqueles elementos que já foram vistos (FLUSSER, 2002).

A qualidade do papel, o uso de capas e páginas coloridas e de tintas especiais, como o dourado, são alguns dos principais atributos físicos da impressão gráfica relacionados à apresentação da revista que contribuem para essa articulação entre imagem e texto. Em relação à formatação gráfica, destaca-se também o uso de vinhetas ilustrativas na composição das páginas. Essas vinhetas, com fortes referências simbólicas, serviam como molduras, separando e decorando ilustrações, poesias, contos, críticas de arte, crônicas e reportagens. Desenhadas por João Turin, Lange de Morretes e Arthur Nísio, dentre outros, essas vinhetas tinham como temática o pinheiro, pinhas, pinhões, sapés e a gralha azul. Algumas delas foram selecionadas e são apresentadas a seguir (prancha 2): 

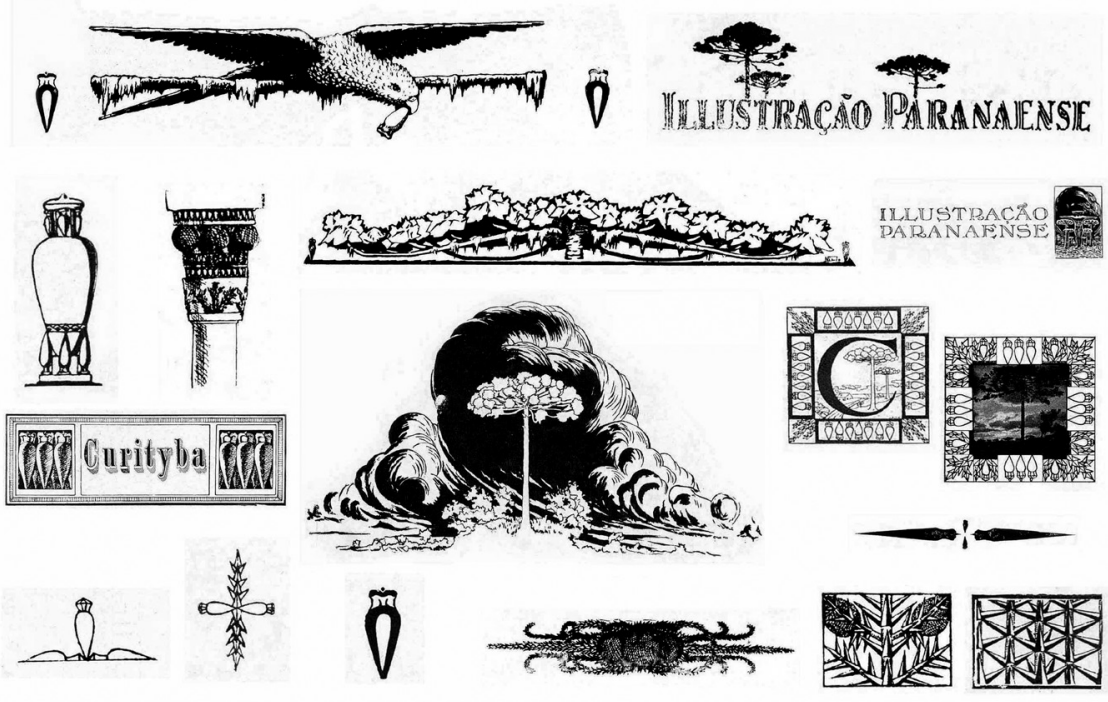

PRANCHA 2 - Vinhetas Ilustrativas da Revista Illustração Paranaense.

Não só as imagens, mas os próprios textos publicados no periódico também exercitavam a visualidade do leitor e não apenas a simples leitura dos caracteres, uma vez que muitos deles se apresentavam em formatos especiais, semelhantes aos da poesia concreta, como Bom dia Paraná!, texto escrito por Romário Martins, reproduzido a seguir (figura 2): 


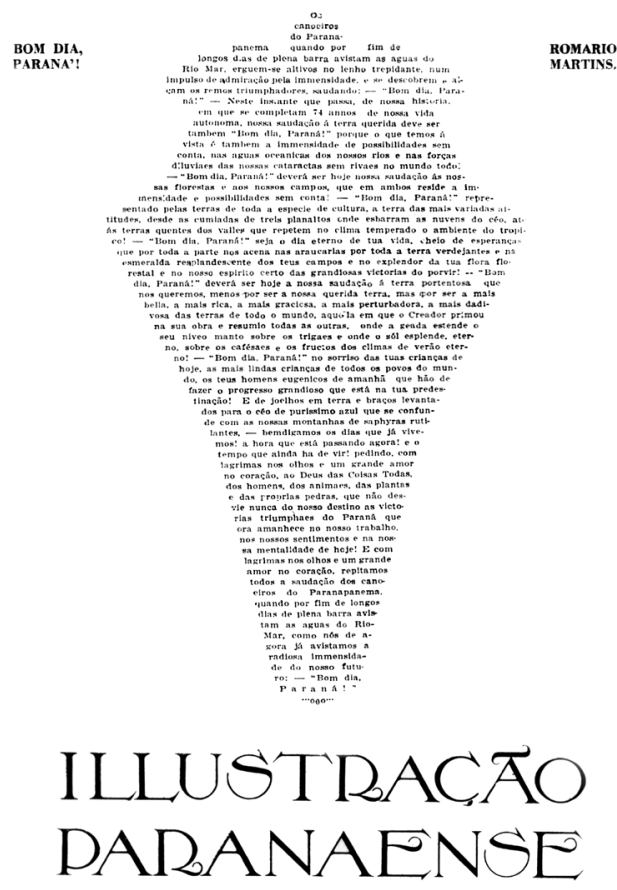

Figura 2 - Martins, R. Bom Dia Paraná!. 1927. In: Illustração Para naense (1927, N. 2, Dez.).

Quanto à questão editorial, a revista contava com a colaboração de artistas e de intelectuais paranaenses. Os artistas plásticos se encarregavam da tarefa de ilustrar os textos ou simplesmente divulgavam suas obras, quando estas apareciam reproduzidas como tema principal. Essa condição proporcionada pela revista só se tornou possível porque esse período é marcado pela reprodutibilidade técnica, que mesmo causando a perda da "aura" da obra de arte, ou seja, de seu estatuto como obra original, ao mesmo tempo proporciona o aumento das ocasiões em que a mesma pode ser exposta (BENJAMIN, 2000). Abaixo estão alguns exemplos de obras reproduzidas no periódico (prancha 3): 


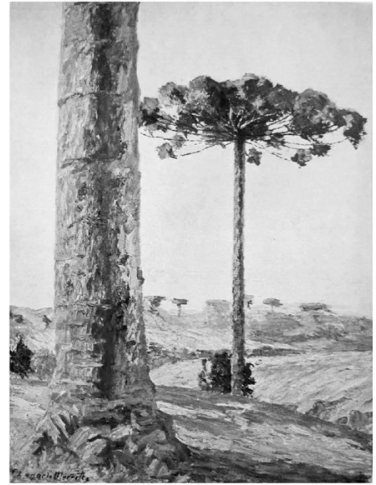

(1)

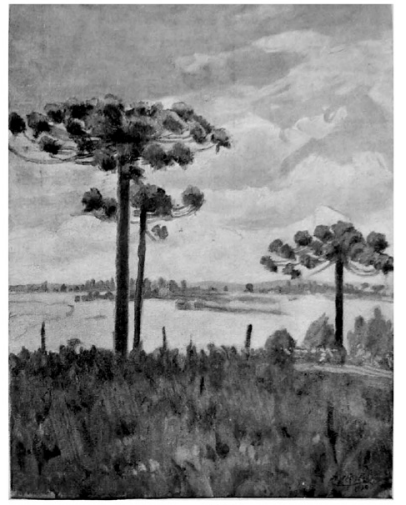

(4)

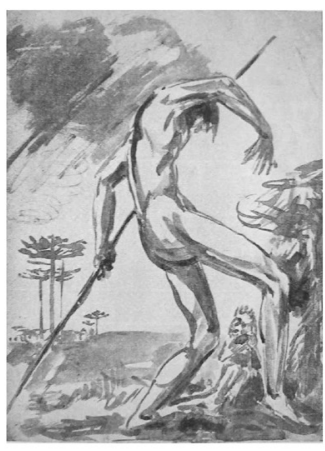

(2)

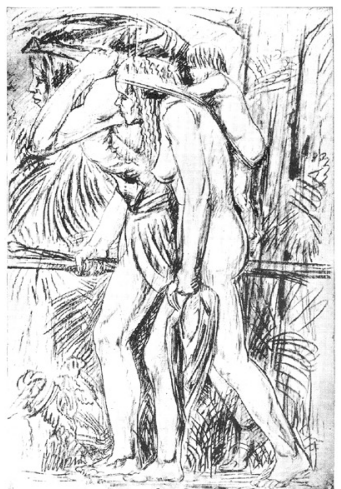

(5)

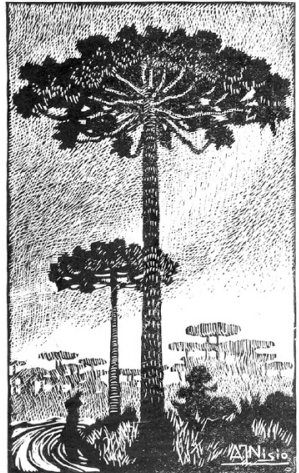

(3)

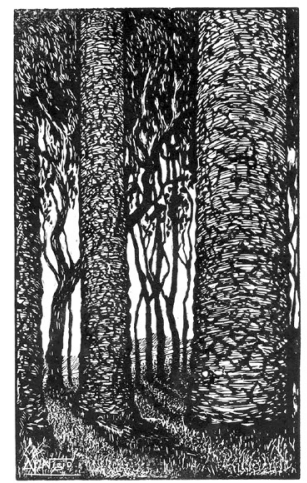

(6)

PRANCHA 3 - Desenhos, Pinturas e Gravuras.

NOTA: (1) MORRETES, F. L. de. Dominadores solitários. Pintura. In: ILLUSTRAÇÃO PARANAENSE, 1930, n. 6, jun.

(2) TURIN, J. A dança do cacique e o Saci-Pererê. Desenho aquarelado. In: ILLUSTRAÇÃO PARANAENSE, 1930, n. 8 ago.

(3) NÍSIO, A. Pinheiro. Xilogravura. In: ILLUSTRAÇÃO PARANAENSE, 1928, n. 3 mar.

(4) ANDERSEN, A. Cajuru. Pintura. In: ILLUSTRAÇÃO PARANAENSE, 1930, n. 5. maio.

(5) TURIN, J. A volta da caça. In: ILLUSTRAÇÃO PARANAENSE, 1928, n. 3 mar.

(6) NÍSIO, A. Troncos de pinheiros. Xilogravura. In: ILLUSTRAÇÃO PARANAENSE, 1928, n. 6 , jun. 
A tabela 1, a seguir, apresenta os resultados de um levantamento acerca dos artistas plásticos e fotógrafos colaboradores e a quantidade de suas obras publicadas na revista entre 1927 e 1930:

\section{TABELA 1 - Principais Artistas Plásticos e Fotógrafos Colaboradores e Obras.}

\begin{tabular}{|c|c|c|c|c|c|}
\hline \multirow[b]{2}{*}{$\begin{array}{l}\text { Artistas Plásticos } \\
\text { e Fotógrafos }\end{array}$} & \multicolumn{4}{|c|}{ Ano } & \multirow[b]{2}{*}{ Total } \\
\hline & $\begin{array}{c}1927 \\
\text { (n. } 1 \text { a } 2)\end{array}$ & $\begin{array}{c}1928 \\
\text { (n. } 1 \text { a } 12)\end{array}$ & $\begin{array}{c}1929 \\
\text { (n. } 1 \text { a 12) }\end{array}$ & $\begin{array}{c}1930 \\
\text { (n. } 1 \text { a } 8)\end{array}$ & \\
\hline Alfredo Andersen & 1 & 6 & 6 & 13 & 26 \\
\hline Antonio Carneiro & - & - & - & 2 & 2 \\
\hline Arthur Nísio & 3 & 7 & 2 & 3 & 15 \\
\hline Arthur Wischral & - & - & 2 & - & 2 \\
\hline A. Weiss & - & - & 3 & - & 3 \\
\hline Braun & 3 & - & - & - & 3 \\
\hline Bruno Lechowski & - & 2 & - & - & 2 \\
\hline E. Luhm & - & - & - & 3 & 3 \\
\hline Eloy & - & - & 6 & - & 6 \\
\hline $\begin{array}{c}\text { Frederico } \\
\text { Guilherme Virmond }\end{array}$ & - & - & - & 3 & 3 \\
\hline $\begin{array}{c}\text { Frederico Lange } \\
\text { de Morretes }\end{array}$ & 2 & 14 & - & 5 & 21 \\
\hline Gustavo Kopp & - & 3 & 3 & 2 & 8 \\
\hline Hanseni & - & 1 & 1 & 1 & 3 \\
\hline Heisler & 2 & 13 & 9 & 18 & 42 \\
\hline $\begin{array}{c}\text { Hermann } \\
\text { Schiefelbein } \\
\end{array}$ & 1 & 1 & - & - & 2 \\
\hline J. Bernardelli & - & 1 & - & 1 & 2 \\
\hline J. Dunin & 1 & 1 & 1 & - & 3 \\
\hline John Henri Elliot & - & - & 2 & - & 2 \\
\hline João Baptista Groff & 6 & 22 & 26 & 26 & 80 \\
\hline João Ghelfi & - & 1 & 1 & - & 2 \\
\hline
\end{tabular}




\begin{tabular}{|c|c|c|c|c|c|}
\hline João Turin & 4 & 22 & 15 & 16 & 57 \\
\hline José Daros & - & - & 1 & 2 & 3 \\
\hline José Peon & - & 1 & 2 & - & 3 \\
\hline Léo Cobbe & 1 & 1 & - & - & 2 \\
\hline Levino Fanzeres & - & 1 & 2 & 1 & 4 \\
\hline Linzmeyer (Estúdio) & 4 & 11 & 10 & 7 & 32 \\
\hline $\begin{array}{c}\text { Maria Amélia } \\
\text { d'Assumpção }\end{array}$ & 1 & 2 & 2 & 2 & 7 \\
\hline $\begin{array}{c}\text { Pamphilo } \\
\text { d'Assumpção }\end{array}$ & 4 & - & - & 1 & 5 \\
\hline $\begin{array}{c}\text { Photo Brasil } \\
\text { (Estúdio) }\end{array}$ & - & - & - & 4 & 4 \\
\hline $\begin{array}{c}\text { Photo Studio } \\
\text { (Estúdio) }\end{array}$ & - & - & - & 4 & 4 \\
\hline $\begin{array}{c}\text { Povos indígenas } \\
\text { (artesanato) }\end{array}$ & 2 & 3 & - & - & 5 \\
\hline \begin{tabular}{c} 
Theodoro De Bona \\
\hline \begin{tabular}{l} 
Zaco Paraná \\
\hline
\end{tabular}
\end{tabular} & - & 13 & 3 & 2 & 18 \\
\hline
\end{tabular}

FONTE: Dados com base no levantamento realizado pelo autor a partir da ILLUSTRAÇÃO PARANAENSE (1927-1930).

NOTA: (1) Artistas com apenas uma participação em todo período foram excluídos.

(2) Sinal convencional utilizado:

- Dado numérico igual a zero.

É interessante notar o que esses dados revelam: os nomes dos artistas colaboradores e a quantidade de obras publicadas. Em ordem decrescente, dentre os artistas plásticos sobressaem João Turin (57), Alfredo Andersen (26), Lange de Morretes (21), Zaco Paraná (18), Arthur Nísio (15) e Theodoro De Bona (13), com desenhos, gravuras, pinturas e esculturas. Dentre os fotógrafos sobressai João Baptista Groff (80), com o maior número de fotografias reproduzidas. Essas informações fornecem um panorama dos recursos visuais utilizados pela equipe editorial da revista e apontam para a dependência mútua entre essa equipe e os artistas e fotógrafos. 
É preciso lembrar ainda, que a revista servia como um local para que os artistas exibissem suas obras, principalmente devido à falta, naquele momento, de salões oficiais e espaços institucionalizados para a realização de exposições. Somente em 1931 surgiu o Salão Paranaense, organizado pela Sociedade de Artistas do Paraná, mas este teve curta duração. Em 1944 seria criado o Salão Paranaense de Belas Artes, vigente até os dias de hoje. Naquela época as exposições eram então realizadas em espaços públicos e comerciais improvisados, feiras ao ar livre ou em ateliês particulares. A tabela 2 informa o tipo de arte reproduzida na revista durante seu período de existência:

TABELA 2 - Tipo de Arte Reproduzida.

\begin{tabular}{|c|c|c|c|c|c|}
\hline \multirow{2}{*}{ Tipo de arte } & \multicolumn{4}{|c|}{ Ano } & \multirow{2}{*}{ Total } \\
\cline { 2 - 5 } & $\begin{array}{c}1927 \\
\text { (n. 1 a 2) }\end{array}$ & $\begin{array}{c}1928 \\
\text { (n. 1 a 12) }\end{array}$ & $\begin{array}{c}1929 \\
\text { (n. 1 a 12) }\end{array}$ & $\begin{array}{c}1930 \\
\text { (n. 1 a 8) }\end{array}$ & \\
\hline Desenhos e gravuras & 15 & 44 & 26 & 17 & 102 \\
\hline Pinturas & 2 & 12 & 14 & 30 & 58 \\
\hline Esculturas & 4 & 26 & 12 & 15 & 57 \\
\hline Fotografias & 17 & 48 & 56 & 64 & 185 \\
\hline
\end{tabular}

FONTE: Dados com base no levantamento realizado pelo autor a partir da ILLUSTRAÇÃO PARANAENSE (1927-1930).

Como era de se esperar, devido às inovações tecnológicas e a vigência da prática fotográfica no final da década de 1920, dentre as obras reproduzidas, a fotografia ocupa o primeiro lugar (185), seguida pelo desenho e pela gravura (102) e, depois, pelas artes plásticas, com a escultura (57) e a pintura (58) quase empatando a terceira posição dentre os dados levantados. Apesar de a fotografia ter se sobressaído em relação 
às outras modalidades artísticas, havia uma coexistência associativa entre os diferentes tipos de artes visuais e não uma disputa.

Ao analisar as edições da revista desse período de quatro anos, percebese que as artes visuais serviam para diferentes fins. No caso específico da fotografia, os temas eram os mais variados possíveis, assim os propósitos. Tanto a elite política curitibana era mostrada em ensaios fotográficos com poses ensaiadas, que estavam longe de expressar a realidade, como fotografias artísticas eram reproduzidas e ocupavam até mesmo o centro de uma página. Isso pode ser explicado pelo fato do próprio João Baptista Groff, proprietário da revista, ser o autor da maior parte dessas fotos, que mostram a importância dada às questões artísticas (prancha 4). 


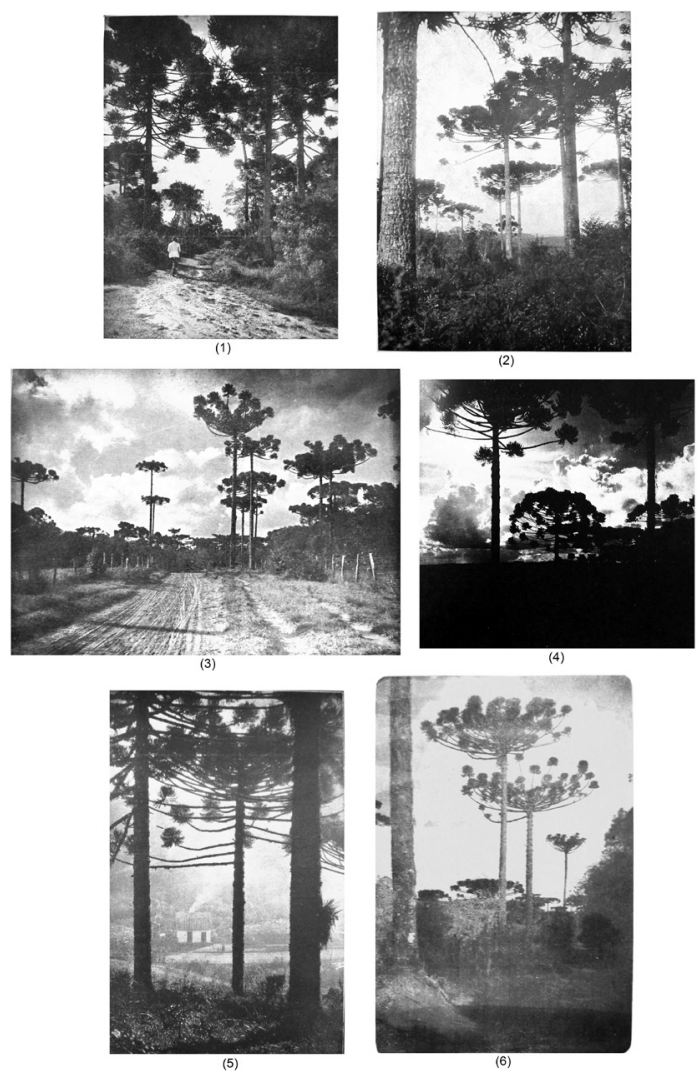

PRANCHA 4 - Fotografias de Pinheiros.

NOTA: (1) GROFF, J. B. Estrada da Villa. In: ILLUSTRAÇÃO PARANAENSE (1930, n. 6, jun.).

(2) GROFF, J. B. Capanema. In: ILLUSTRAÇÃO PARANAENSE (1930, n. 1, jan.).

(3) GROFF, J. B. Natureza paranaense. In: ILLUSTRAÇÃO PARANAENSE (1930, n. 7 , jul.).

(4) GROFF, J. B. Arredores de Curitiba. In: ILLUSTRAÇÃO PARANAENSE (1929, n. 12 , dez.).

(5) GROFF, J. B. Os pinheiros do Capanema. In: ILLUSTRAÇÃO PARANAENSE (1929, n. 5-6, maio-jun.).

(6) GROFF, J. B. Manhã nos arredores de Curitiba. In: ILLUSTRAÇÃO PARANAENSE (1930, n. 8, ago.). 
Em relação ao desenho, à gravura e às artes plásticas, como já foi dito, as obras ora serviam como tema para a crítica de arte, ora serviam para ilustrar textos de diversos colaboradores, cujos nomes são apresentados no quadro 3:

\section{QUADRO 3 - Principais Escritores Colaboradores}

\begin{tabular}{|c|c|c|}
\hline \multicolumn{3}{|c|}{ Autores por ordem alfabética } \\
\hline Adherbal Stresser & Emiliano Pernetta & Nestor de Castro \\
\hline Alberto de Oliveira & Emilio de Menezes & Noemia Carneiro \\
\hline Alcindo Lima & Ermelino de Leão & Octávio de Sá Barreto \\
\hline Aluízio França & Ernesto Luiz de Oliveira & Odilon Negrão \\
\hline Álvaro Moreira & Euclides Bandeira & Pamphilo D'Assumpção \\
\hline Amadeo Mammalella & Francisco Leite & Paulo D'Assumpção \\
\hline Ângelo Guido & Frederico de Marco & Paulo Tacla \\
\hline Anita Philipovsky & Generoso Borges & Plínio Salgado \\
\hline Antonio Corrêa d' Oliveira & Heitor Stockler & Raul Gomes \\
\hline Arnaldo Damasceno Vieira & Hermes Fontes & Rodrigo Junior \\
\hline Augusto Frederico Schimidt & I. Serro Azul & Romário Martins \\
\hline $\begin{array}{l}\text { Bento Munhoz da } \\
\text { Rocha Neto }\end{array}$ & Jayme Ballão Junior & Samuel Cesar \\
\hline Carlos Stevenson & José Muricy & Seraphim França \\
\hline Ciro Silva & Jurandyr Manfredini & Silveira Netto \\
\hline Correia Junior & Lacerda Pinto & Sotero Ângelo \\
\hline Dario Vellozo & Léo Cobbe & Sylvio Amaral \\
\hline David A. Silva Carneiro & Leoncio Correia & Tasso da Silveira \\
\hline Didi Caillet & Mario Poppe & Viriato Ballão \\
\hline
\end{tabular}

FONTE: Levantamento elaborado pelo autor a partir da ILLUSTRAÇÃO PARANAENSE (1927-1930).

NOTA: Foram considerados nessa listagem autores que produziram contos, crônicas, reportagens, críticas de arte e poesias, cuja participação se deu mais de uma vez. 
Embora alguns dos colaboradores citados no quadro acima não tivessem formação acadêmica nas áreas em que atuavam, ou já tivessem outras profissões que permitiam suas subsistências, muitos contribuíam com contos, poesias, críticas de arte, crônicas e reportagens. Por outro lado, nessa mesma listagem aparecem nomes de escritores consagrados, alguns deles inclusive eram poetas simbolistas. Dentre os nomes dos intelectuais colaboradores mais importantes merecem destaque: Euclides Bandeira, Emiliano Pernetta, Emílio de Menezes, Dario Vellozo, Leoncio Correia, Nestor de Castro, Silveira Netto, Tasso da Silveira e Romário Martins.

Atenção especial era dada aos escritos de Romário Martins, cujos contos sobre mitos e lendas indígenas eram publicados na página de abertura da revista. Considerado o idealizador do Movimento Paranista, Romário Martins foi um dos personagens mais influentes para os intelectuais e artistas paranaenses. Ao longo de sua trajetória, empenhouse na divulgação da história e do folclore do Estado do Paraná, sendo um dos fundadores do Instituto Histórico e Geográfico do Paraná, criado em 1900, e principal fundador do Centro Paranista, criado em 1927. Dedicou-se à pesquisa documental e elaborou leis, dentre elas, a da criação da Bandeira e do Brasão do Estado do Paraná e a da proposição da data de 29 de março para o aniversário da cidade de Curitiba.

No que se refere às principais críticas de arte publicadas na revista, elas refletem, de certa maneira, a interdependência entre artistas e escritores. Essa dependência contribuía de forma significativa para o reconhecimento social e artístico dos primeiros, na medida em que colocava suas carreiras e obras à mostra a partir de elementos eleitos como significativos. Nesse ponto, há de se considerar, conforme ZOLBERG (2006, p. 38), que uma obra de arte não pode ser inteiramente entendida apenas por suas qualidades estéticas, mas também pelas suas condições externas, sendo um momento num processo que envolve a colaboração de mais de um ator, trabalhando por meio de certas instituições sociais e seguindo tendências historicamente observáveis. Além disso, segundo HEINICH (2008, p. 88), uma obra de arte só encontra espaço como tal a partir da cooperação de uma "rede complexa de atores", com marchands, 
colecionadores, críticos, peritos, avaliadores, conservadores, restauradores, curadores e historiadores da arte. E ainda, ela quase não encontraria público consumidor sem intérpretes, editores e impressores. É justamente nesse sentido que a crítica de arte pode ser aqui situada, enquanto "mediação" entre artista e público.

Além dos textos literários e das críticas de arte, as reportagens locais sobre as transformações ocasionadas pela vida moderna também eram constantes. Um suplemento que acompanhava uma das edições da revista mostra muito bem o ideal de modernidade vigente na época. Intitulado 10 minutos de leitura sobre o Paraná, esse livreto trazia como texto de abertura um artigo de Romário Martins que fazia uma retrospectiva da importância social, econômica e cultural do pinheiro para o Paraná e sua população, desde as tribos indígenas originárias da região até aquele momento, apontando ainda para o futuro. Já o segundo texto, cuja autoria cita as iniciais E. S., está dividido em dois blocos, sendo que o primeiro deles apresenta atualidades paranaenses daquele período e o segundo, um projeto turístico com as despesas contabilizadas para uma excursão no Paraná (ILLUSTRAÇÃO PARANAENSE, 1929).

É possível perceber que tanto os pontos turísticos de caráter geográfico quanto os de importância cultural daquele período serviam como imagens e símbolos que representavam o Paraná. Entre os desenhos que ilustravam o livreto estavam estilizações de pinheiro e pinhões de Lange de Morretes e de João Turin, o Escudo do Estado do Paraná, o retrato de Affonso Camargo, Presidente do Estado, e os mapas do Paraná e do Brasil. As fotos, de autoria de João Baptista Groff, tinham como tema elementos locais: pinheiros; a Estrada de Ferro do Paraná (o Viaduto Carvalho e o Vale do Ipiranga); os Saltos de Guaíra e do Iguaçu; Vila Velha; a Escola Normal de Paranaguá; a Universidade do Paraná, a Catedral e a Rua XV de Novembro em Curitiba; a Escola Normal e a Rua $\mathrm{XV}$ de Novembro em Ponta Grossa; as praias de Guaratuba e as grutas dos arredores de Curitiba. As fotos em que aparecem pessoas retratavam costumes locais, os jogos de futebol e os restaurantes e chás de Curitiba. 
Os mesmos elementos visuais e textuais dessa publicação apareceriam três anos depois em Curityba: capital do Estado do Paraná (MARTINS, 1931), outra edição da mesma revista, só que desta vez com textos históricos de Romário Martins, fotos de João Baptista Groff e capa de Lange de Morretes. Além das imagens que figuravam na publicação anteriormente comentada, nesta havia um destaque para as praças e monumentos de Curitiba, os prédios governamentais, os bondes e as avenidas da cidade. Entre os temas tratados por Romário Martins estavam a fundação de Curitiba, a cidade em 1931, a arte e os artistas e o mesmo projeto turístico para uma excursão.

É interessante notar também o grande número de propagandas dos anunciantes locais, não só nessas duas publicações comentadas, mas no período de existência da Illustração Paranaense, na qual várias empresas de diversos ramos de atividade anunciavam produtos e serviços, como bebidas e alimentos, cosméticos e medicamentos, artigos de moda e vestuário, automóveis e peças automobilísticas, equipamentos eletrônicos e eletrodomésticos, prestação de serviços e comércio. O quadro 4 apresenta uma listagem com os nomes dos principais anunciantes do periódico durante os três anos em que o mesmo circulou. 


\section{QUADRO 4 - Principais Anunciantes.}

\begin{tabular}{|c|c|c|}
\hline Ramo de atividade & Empresa & Produtos ou serviços \\
\hline \multirow{14}{*}{ Bebidas e Alimentos } & Cervejaria Atlantica Curityba & Cerveja Bock Bier Atlantica \\
\hline & Ouro Fino & Água mineral Ouro Fino \\
\hline & Leão Junior \& Cia. & Chá Matte Leão \\
\hline & F. F. Fontana \& Cia. & Chá Mate Ildefonso \\
\hline & David Carneiro \& Cia. & Chá Mate Real \\
\hline & Meirelles \& Souza & Chá Mate Negrita \\
\hline & Hugo Cini \& Cia. & Cerveja Aguia \\
\hline & - & Leite condensado Vigor \\
\hline & Todeschini e Irmãos & Café e macarrão Tosca \\
\hline & A. Büchner \& Cia. & Bebida Láctea Ovomaltine \\
\hline & - & Macarrão Catini \\
\hline & - & Café Paraná \& Café Gaucho \\
\hline & Fratelli Gancia \& Co. & $\begin{array}{l}\text { Vermutes, vinhos e } \\
\text { champanhes Gancia }\end{array}$ \\
\hline & - & Cerveja Pilsen \\
\hline \multirow{7}{*}{$\begin{array}{l}\text { Cosméticos } \\
\text { e Medicamentos }\end{array}$} & Magnesia S. Pellegrino & Purgante \\
\hline & Heitor Gomes \& Cia. & Remédios \\
\hline & - & Loção para cabelos Kiou-Nouk \\
\hline & Lattes \& Cia. & Lança perfumes Rodo e Rigoletto \\
\hline & Luhn & Perfumes, essências, anilinas \\
\hline & - & $\begin{array}{l}\text { Tônico fortificante } \\
\text { Vinho Creosotado }\end{array}$ \\
\hline & - & $\begin{array}{l}\text { Fortificante Haematogen } \\
\text { Dr. Hommel }\end{array}$ \\
\hline \multirow{6}{*}{ Moda e Vestuário } & Casa Gloger & Chapéus \\
\hline & Maison Blanche & Roupas infantis \\
\hline & Casa Abdo & Loja de roupas \\
\hline & Braunz & Loja de roupas \\
\hline & Pelleria Renard & Casacos de peles, roupas \\
\hline & Vicent Cury \& Cia. & Chapéus \\
\hline
\end{tabular}




\begin{tabular}{|c|c|c|}
\hline \multirow{4}{*}{ Moda e Vestuário } & $\begin{array}{l}\text { Chapelaria Modelo, } \\
\text { Joaquim Alves dos Reis }\end{array}$ & Chapéus e calçados \\
\hline & Galeria das Sedas & Roupas \\
\hline & Favorita & Calçados femininos \\
\hline & Moreira Campos \& Cia. & Concessionária \\
\hline \multirow{5}{*}{$\begin{array}{l}\text { Automóveis e peças } \\
\text { automobilísticas }\end{array}$} & $\begin{array}{l}\text { G. Nickel Junior \& Cia. } \\
\text { (distribuidor General } \\
\text { Motors of Brazil) }\end{array}$ & Automóveis, peças e acessórios \\
\hline & $\begin{array}{l}\text { Ford Motor Company } \\
\text { Exports. In. }\end{array}$ & Automóveis e peças \\
\hline & E. A. Kimmel (distribuidor) & Pneus Firestone \\
\hline & Walter Kipper & Oficina de automóveis \\
\hline & Eisenbach \& Cia. & Automóvel Marmom \\
\hline \multirow{9}{*}{$\begin{array}{l}\text { Equipamentos } \\
\text { eletrônicos } \\
\text { e eletrodomésticos }\end{array}$} & Casa Hertel & $\begin{array}{l}\text { Gramofones, rádios, discos, } \\
\text { instrumentos musicais, pianos, } \\
\text { máquinas de escrever }\end{array}$ \\
\hline & $\begin{array}{l}\text { Sociedade Technica } \\
\text { Bremensis Ltda. }\end{array}$ & Distribuidora de máquinas \\
\hline & F. Essenfelder \& Cia. & Pianos \\
\hline & Voigtländer & $\begin{array}{l}\begin{array}{l}\text { Máquinas fotográficas, filmes, } \\
\text { chapas e papéis Satrap }\end{array} \\
\end{array}$ \\
\hline & Foto Groff & Material fotográfico, revelações \\
\hline & General Eletric & Refrigerador, radiola \\
\hline & $\begin{array}{l}\text { José Hauer Jr. \& Cia. } \\
\text { (Casa Metal) }\end{array}$ & Rádio, válvulas \\
\hline & Casa Salomão & Móveis \\
\hline & Philips & Lâmpadas, receptor \\
\hline \multirow{5}{*}{$\begin{array}{l}\text { Prestação de serviço } \\
\text { e Comércio }\end{array}$} & $\begin{array}{l}\text { Companhia Telephonica } \\
\text { Paranaense Ltda. }\end{array}$ & Telefonia \\
\hline & Roberto Machado \& Cia. & $\begin{array}{l}\text { Fábrica de tecidos (bolsas para } \\
\text { erva-mate, café e cereais) }\end{array}$ \\
\hline & Leão Junior \& Cia. & Seguros \\
\hline & $\begin{array}{l}\text { Neuchatel Companhia } \\
\text { Auxiliar de Viação e Obras }\end{array}$ & Calçamento asfáltico \\
\hline & $\begin{array}{l}\text { Banca Francese e Italiana } \\
\text { Per l'America del Sud }\end{array}$ & Correspondente bancário \\
\hline
\end{tabular}




\begin{tabular}{|c|l|l|}
\hline \multirow{5}{*}{\begin{tabular}{|l|} 
Prestação de serviço \\
e Comércio
\end{tabular}} & A. Neumann & Professor de violino \\
\cline { 2 - 3 } & João Nociti & Representações \\
\cline { 2 - 3 } & $\begin{array}{l}\text { Companhia Força e } \\
\text { Luz do Paraná }\end{array}$ & Linhas elétricas \\
\cline { 2 - 3 } & $\begin{array}{l}\text { Industrias Reunidas } \\
\text { F. Matarazzo }\end{array}$ & Moinho Matarazzo \\
\cline { 2 - 3 } & Impressora Paranaense & Gráfica \\
\cline { 2 - 3 } & Banco do Estado do Paraná & Banco \\
\cline { 2 - 3 } & Guimarães \& Cia. & Seguros \\
\cline { 2 - 3 } & David Carneiro \& Cia. & Seguros \\
\cline { 2 - 3 } & Foto Groff & Material fotográfico, revelações \\
\cline { 2 - 3 } & Romani, Franchi \& Cia. & Importadora \\
\cline { 2 - 3 } & Da Veiga \& Cia. & Seguros de automóveis \\
\cline { 2 - 3 } & França \& Cia.Ltda. & Livraria Mundial \\
\hline
\end{tabular}

FONTE: Levantamento realizado pelo autor a partir da ILLUSTRAÇÃO PARANAENSE (1927-1930).

NOTA: (1) Todos os anunciantes selecionados aparecem pelo menos em dois números da revista.

(2) Sinal convencional utilizado:

- Sem referência.

Dessa listagem, alguns produtos se destacam, como a erva-mate, que simboliza um dos ciclos econômicos do Estado. Já outros anúncios ilustram o início da urbanização da cidade de Curitiba e as mudanças ocorridas com a vida moderna, como a venda de automóveis e o oferecimento de serviços automotivos, os eletrodomésticos disponíveis no mercado, a diferenciação e o nivelamento social por meio dos cosméticos, da moda e vestuário, o desenvolvimento dos meios de comunicação de massa por meio da indústria da música, da indústria gráfica e dos serviços de telefonia, a prática fotográfica e os serviços oferecidos pelos bancos e pelas companhias de seguros.

A maior parte desses anúncios publicitários ocupava as páginas iniciais da revista, embora algumas vezes fossem inseridos no meio ou no fim. Além desses anúncios, embora não tenham sido encontrados 
documentos oficiais, a revista também recebia incentivo financeiro estatal, por parte do então Presidente do Estado, Affonso Camargo. Em troca desse incentivo, fazia-se apologia à política da época por meio de publicações de desenhos e fotografias que retratavam os políticos, dentre eles o próprio Affonso Camargo. Para tanto, foram selecionadas duas imagens que evidenciam como se dava essa relação. A primeira delas (figura 6) é uma foto posada do Presidente do Estado com sua família: sua esposa, ao seu lado direito, e suas duas filhas, em pé logo atrás do casal. A foto, produzida por João Baptista Groff, reproduz o ideal de uma família perfeita "de um ilustre estadista", como afirma a frase abaixo da moldura, esta que inclui também um dos símbolos oficiais do Estado do Paraná no canto superior esquerdo.

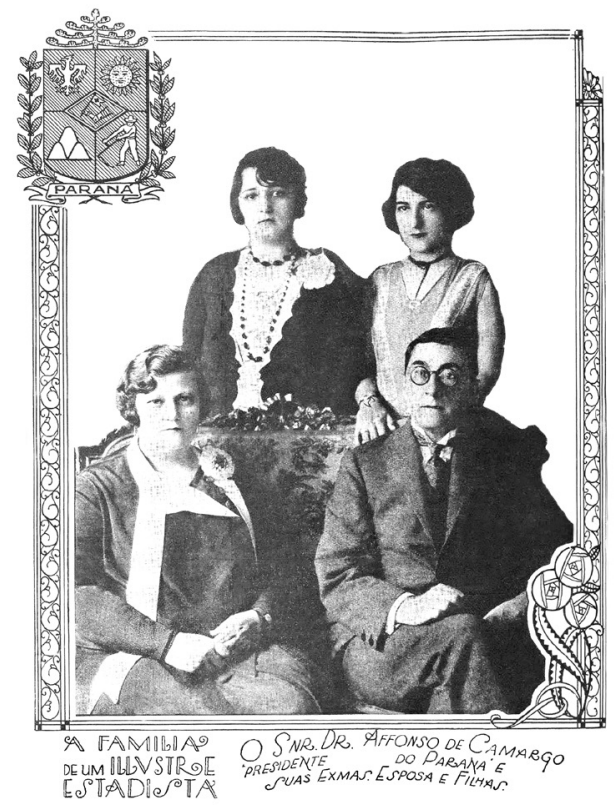

Figura 6 - Groff, J. B. A Família de um Ilustre In: Estadista. 1928. Illustração Paranaense (1928, n. 2, Mar.). 
A segunda imagem (figura 7) reproduz um desenho de autoria de Alfredo Andersen, que faz uma analogia entre o político em questão e O Semeador, tema, com forte referência na História da Arte e que inclusive resultou na escultura mais famosa de Zaco Paraná. Esse tema é utilizado aqui de maneira sincrética para informar sobre uma das campanhas políticas de Affonso Camargo. No desenho, além da posição do político andando e semeando a terra, a analogia também pode ser percebida na comparação entre a imagem entrelaçada na letra s da frase "Semeia Semeador!", acima da figura.

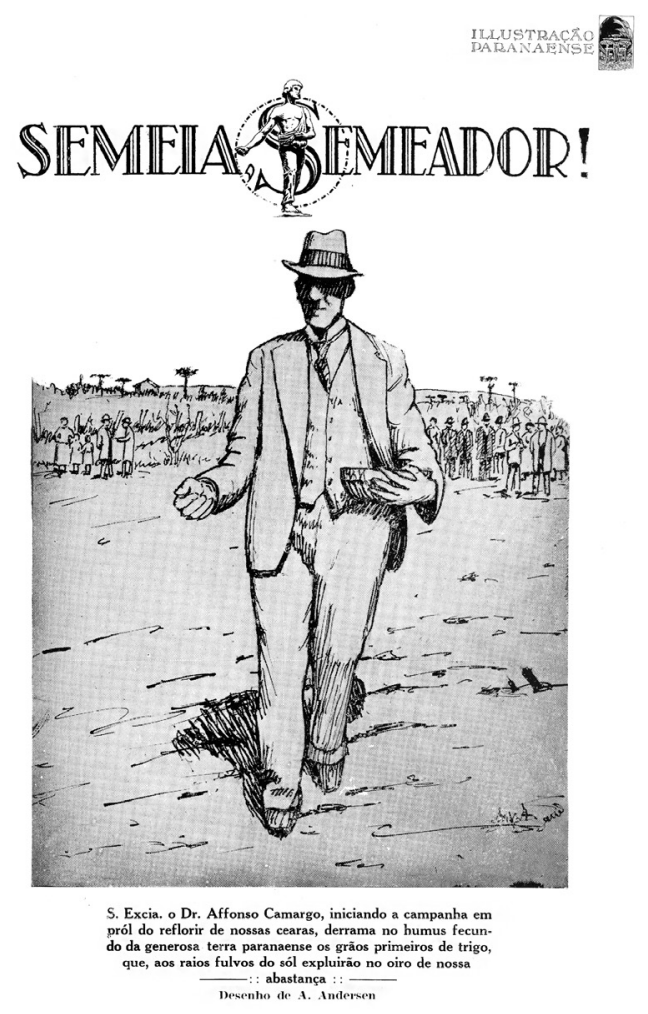

Figura 7 - Andersen, A. Semeia Semador!. 1928. In: illustração Paranaense (1928, n. 6, Jun.). 
Em parte, esses elementos ajudam a entender como a revista manteve-se em circulação. Outro fator relevante é a busca, por parte da Illustração Paranaense, de melhoria na produção gráfica e na redução de custos na produção. Algumas informações permitem conhecer a estrutura organizacional e os recursos econômicos que mantinham a publicação da revista. Ao longo dos números publicados, João Baptista Groff aparece como "diretor-proprietário". Inicialmente a Redação Provisória da revista situava-se na Rua XV de Novembro, n. 51-A e a Oficina na Rua Marechal Deodoro, n. 63-A (ILLUSTRAÇÃO PARANAENSE, 1927, n. 1, nov.). Dois anos depois, a revista passou a ser impressa em oficina própria, junto à redação e administração, localizadas na Rua Dr. Muricy, n. 850. A equipe editorial relatava a melhoria da qualidade da impressão, já que havia sido adquirido novo maquinário, importado da Alemanha (ILLUSTRAÇÃO PARANAENSE, 1929, n. 8-11, nov.). Outro fato interessante ocorrido no ano de 1929 é a pequena mudança do estilo do desenho da capa realizado por João Turin.

Os preços de venda da revista e dos anúncios nela publicados também são relevantes para conhecer seus recursos econômicos. Quando lançada em novembro de 1927, a revista custava $1 \$ 500$ (mil e quinhentos réis). Nas edições seguintes, passaria a custar $2 \$ 000$, conforme consta nos números 2 e 6 de 1928. O periódico também oferecia assinaturas anuais. Os preços iniciais para publicação de anúncios eram os seguintes: $200 \$ 000$ para anúncios de página inteira, $120 \$ 000$ para meia página, $60 \$ 000$ para um quarto de página e $50 \$ 000$ para um oitavo de página. As publicações especiais tinham os seguintes preços: $300 \$ 000$ para página inteira ilustrada, $200 \$ 000$ para meia página, $20 \%$ a mais para duas cores e descontos conforme previam os contratos (ILLUSTRAÇÃO PARANAENSE, 1927, n. 1, nov.). Em novembro de 1929 a revista voltaria ao preço inicial de $1 \$ 500$, mas os valores para publicação de anúncios aumentariam³: $250 \$ 000$ para

\footnotetext{
${ }^{3} \mathrm{O}$ motivo da mudança do custo da revista para os leitores aparece da seguinte forma num fragmento de um texto publicado em página distinta: "Para maior divulgação dos nomes dos nossos colaboradores resolvermos reduzir à $1 \$ 500$ o preço da Illustração - melhorando cada vez mais e reduzindo ao minimo possivel o custo da nossa publicação, estamos certos de que
} 
uma página, $150 \$ 000$ para meia página, $80 \$ 000$ para um quarto de página e $50 \$ 000$ para um oitavo de página. As publicações especiais custavam: 500\$000 para página ilustrada, $300 \$ 000$ para meia página ilustrada e 30\% a mais para duas cores (ILLUSTRAÇÃO PARANAENSE, 1929, n. 8-11, nov.).

Tendo circulado com frequência até 1930, a revista interrompeu sua publicação possivelmente em decorrência da crise gerada pela Revolução de 1930 e de suas consequências. Os dois últimos números do ano de 1930 já apontavam para sua decadência, especialmente em relação à qualidade artística. O número 9, do mês de outubro, ao invés do desenho de João Turin, apresentava como capa uma foto do General Plínio Tourinho, então Comandante e Chefe das Forças Revolucionárias do Paraná e de Santa Catarina. Já a capa do mês seguinte fazia forte propaganda política, estampando uma foto do então líder revolucionário Getúlio Vargas acenando para a multidão. Esses dois números traziam também várias fotos da Revolução de 1930 no Paraná, produzidas por João Baptista Groff, que fotografou e filmou esse episódio da história brasileira. Conforme apresentado na prancha 5:
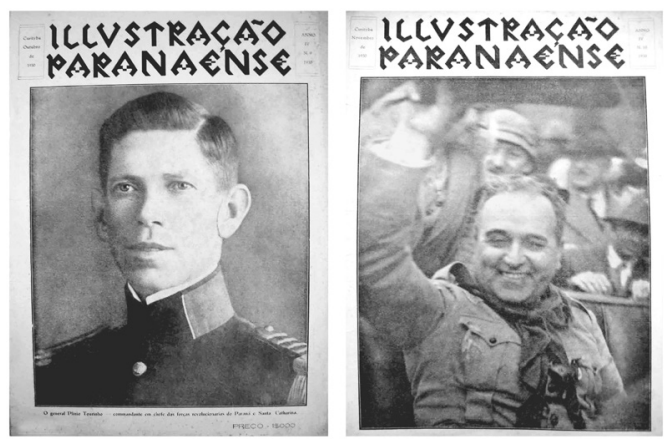

PRANCHA 5 - Capas dos Dois Últimos Números de 1930 da Illustração Paranaense. In: Illustração Paranaense, 1930, n. 9, Out. e n. 10, Nov.

os leitores de Illustração Paranaense divulgarão os seus meritos, tornando-a uma da maiores realizações jornalisticas, no genero, em todo o paiz. - Illustração Paranaense, espera, pois, que cada leitor nos proporcione novos leitores, concorrendo desse modo para o desenvolvimento intellectual da Nação" (ILLUSTRAÇÃO PARANAENSE, 1929, n. 8-11, nov.). 
A revista voltou a ser editada em fevereiro de 1933, mas sem as mesmas pretensões. Mesmo com a volta da capa original desenhada por João Turin, esse número focalizava a Exposição Industrial de 1932, apresentando um histórico das exposições industriais realizadas no Paraná, no Rio de Janeiro e no exterior. A revista trazia ainda uma reportagem sobre Curitiba, com dados estatísticos da cidade e comentários sobre os principais pontos turísticos do Paraná. Dentre os pontos turísticos destacados em forma de fotografia estavam: a Praça Tiradentes, a Universidade do Paraná, o monumento ao Barão do Rio Branco e a Prefeitura de Curitiba (com sede no Paço da Liberdade), a Praça General Osório e a Herma Domingos Nascimento, os arredores da cidade (fotos com pinheiros) e os Saltos do Iguaçu. Portanto, há uma mudança em relação à representação do Paraná, com ênfase principalmente em locais que reverenciam a memória histórica e a vida moderna, como as novas edificações públicas, as praças e os monumentos, e não mais a natureza paranaense. Assim sendo, os três últimos números da revista não apresentavam a mesma qualidade gráfica e editorial dos quatro primeiros anos, muito menos expressavam qualquer intenção artística.

\section{CONSIDERAÇÕES FINAIS}

A revista Illustração Paranaense foi veículo para promoção de um repertório de imagens (fotografias, obras de arte e símbolos) capaz de definir uma identidade local, grande inquietação de um grupo específico. Nessa direção, artistas e intelectuais procuravam se diferenciar dos políticos construindo e promovendo uma identidade própria a partir da realização de suas obras.

No referido estudo, constatou-se que a proposta artística se manteve com certa independência em relação aos ideais políticos, especialmente em relação à criação. A preocupação com a identidade local não resulta, tão simplesmente, da subordinação da arte à política. 
Embora outros estudos afirmem que a arte se colocava à disposição dos interesses políticos, no que tange à criação, pode-se dizer que os artistas tinham liberdade em seu próprio trabalho. Nesse jogo de interesses, a arte usufruía da política e a política usufruía da arte.

\section{BIBLIOGRAFIA}

BENJAMIN, Walter. A obra de arte na época de sua reprodutibilidade técnica. In: LIMA, Luiz Costa. (org.). Teoria da cultura de massa. São Paulo: Paz e Terra, 2000. pp. 215-254.

BOURDIEU, Pierre. As regras da arte: gênese e estrutura do campo literário. São Paulo: Companhia das Letras, 1996.

ELIAS, Norbert. Introdução à sociologia. Lisboa: Edições 70, 1999.

FLUSSER, Vilém. Filosofia da caixa preta: ensaios para uma futura filosofia da fotografia. Coleção Conexões. Rio de Janeiro: Relume Dumará, 2002.

HEINICH, Nathalie. A Sociologia da Arte. Coleção Ciências Sociais. Bauru: Edusc, 2008.

ILLUSTRAÇO PARANAENSE: Mensário paranista de arte e actualidades. Curitiba, Ano I-IV, 1927-1930.

- 10 minutos de leitura sobre o Paraná. Fotos de João Baptista Groff. Curitiba: Illustração Paranaense, 1929. 34 p. Suplemento.

MARTINS, Romário. Curityba: capital do Estado do Paraná. Fotos de J. B. Groff e capa de Lange de Morretes. Curitiba: Illustração Paranaense, 1931.

. Paranística. A divulgação, Curitiba, Ano I, n. 3-4, pp. 37-39, fev./ mar. 1948. 
- Programma Geral do Centro Paranista: fundado em Curityba pelo Instituto Histórico e Pela Sociedade de Agricultura. Curitiba: Livraria Mundial, França \& Cia. Ltda, 1927.

SALTURI, Luis Afonso. Gerações de artistas plásticos e suas práticas: Sociologia da arte paranaense das primeiras décadas do século XX. Curitiba, 2011. 259 f. Tese (Doutorado em Sociologia) - Setor de Ciências Humanas, Letras e Artes, Universidade Federal do Paraná.

- Paranismo, movimento artístico do sul do Brasil no início do século XX. Periferia: revista de recerca i formació en Antropologia. Espanha, v. 11, pp. 1-22, 2009.

ZOLBERG, Vera. Para uma sociologia das artes. São Paulo: Editora Senac São Paulo, 2006.

\section{ACERVOS PESQUISADOS}

Biblioteca Pública do Paraná.

Casa da Memória de Curitiba.

Museu Paranaense. 